\title{
Integrated nutrition science: from theory to practice in South Africa
}

\author{
$\mathrm{HH}$ Vorster $^{1, *}, \mathrm{BM}$ Margetts ${ }^{1}, \mathrm{CS}_{\text {Venter }}{ }^{1}$ and MP Wissing ${ }^{2}$ \\ 'School of Physiology and Nutrition, Faculty of Health Sciences, North-West University (Potchefstroom Campus), \\ Private Bag X6001, Potchefstroom 2520, South Africa: ${ }^{2}$ School of Psycho-Social and Behavioural Sciences, \\ Faculty of Health Sciences, North-West University (Potchefstroom Campus), Potchefstroom 2520, South Africa
}

\begin{abstract}
Objective: To describe an integrated, holistic conceptual framework and research paradigm for a better understanding of the nutrition transition in middle- and lowincome countries.

Motivation: Current inability effectively to prevent the increasing burden related to changes in food consumption patterns and other health behaviours of populations in transition motivates a new approach for nutrition research and practice. In this proposed approach, broader and integrated dimensions of science and practice may be applied for a better understanding of this complex phenomenon.

Result: Examples from our own studies are given and quoted to illustrate how results from transdisciplinary studies were used to design an integrated, holistic programme to improve quality of life of people infected with HIV.

Conclusion: Based on these experiences it is argued that the more holistic and integrated approach should and could lead to more effective and sustainable interventions to prevent the adverse health consequences of the nutrition transition. At the same time such an approach will contribute to efforts to conserve the environment and also human, living and natural resources.
\end{abstract}

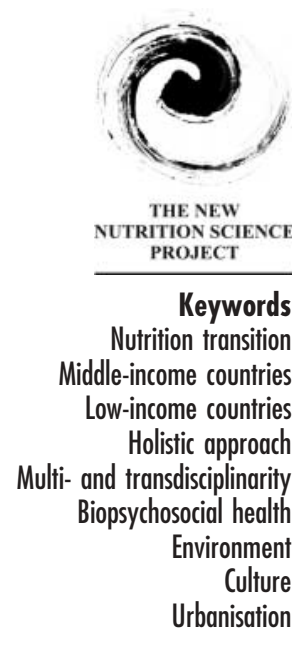

The global health transition, characterised in middleand low-income countries by circumstances and behaviours leading to the double burden of infectious and non-communicable diseases, has focused attention on the inability at present to effectively address nutrition-related diseases on a population level. The 'new map' and broader social and environmental as well as biological dimensions for nutrition science

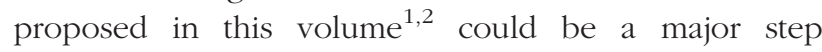
towards a better understanding of all factors influencing human behaviour, and therefore to more appropriate and sustainable interventions to ensure optimum nutrition for all.

The aim of this paper is to describe the holistic and integrated approach that our research group has followed over the last 10 years in studying the nutrition transition in South Africa, in order to make more appropriate recommendations that could lead to a better nutrition and health status of the population.

After a brief outline of the present health transition in South Africa, the nutrition transition is defined and our conceptual framework to study this transition discussed. Some results of this transdisciplinary approach are given.

\section{Discussion}

\section{South Africa: a nation in transition}

South Africa is a unique and extremely relevant country in which to study the nutrition transition. It is a nation in which African, Asian and European cultures have come together in a land with sufficient resources to offer Westernised and modern ways of life to its inhabitants. It is a country in transition: because of its history and recent political changes, problems of inequality, poverty and human rights are now being addressed aggressively. This is accompanied by rapid urbanisation, leading to changes in economic, societal and family structures. Changes in traditional ways of life, value systems and human behaviour are all impacting on the health of the population.

Improvements in the economic environment, better access to health care and better availability of nutritious foods should have resulted in improved health. However, the reverse has been observed. The 2002 South African Health Review ${ }^{3}$ shows that the infant mortality rate per 1000 live births increased from 45.4 deaths in the first year of life in 1998 to 59.0 in 2002. Over the same period the under -5 s mortality rate almost doubled, from 59.4 to 100.0 deaths per 1000 live births. This is probably related to 
Africa and other economically developing regions are now suffering a double burden of obesity, diabetes and other non-communicable diseases, on top of nutritional deficiencies and infectious diseases. Our current approaches are not controlling nutrition-related diseases at population levels. The solution is holistic, integrated, sustainable policies and interventions. These should also conserve the environment, and human, living and physical resources now and in future.

the high HIV/AIDS prevalence. Antenatal testing reported a prevalence of $24.8 \%$ in $2001^{3}$. The stunting prevalence for children aged 1-9 years was $23.8 \%$ in $1999^{3}$. In the same year it was reported that $9.1 \%$ and $29.4 \%$ of adult men and women were obese, while $11.0 \%$ of men and $13.2 \%$ of women suffered from hypertension ${ }^{3}$. These data illustrate that the consequences of under- and overnutrition coexist in South Africa.

\section{The nutrition transition}

The nutrition transition can be defined as a stepwise sequence of characteristic changes in dietary patterns and nutrient intakes associated with societal, economic and cultural changes during the demographic transition of populations ${ }^{4}$. The changes in dietary patterns typically lead to increased intakes of total fat (saturated, omega-6 polyunsaturated and trans-fatty acids), animal protein, sugar and salt; and decreased intakes of plant protein, dietary fibre and other complex carbohydrates ${ }^{5}$. However, there are often also increases in the variety of foods eaten as well as in fruit and vegetable consumption and therefore in micronutrient intakes. But there is no doubt that the dietary changes described for Africans in transition are characterised by increasing consumption of diets associated with higher risk of non-communicable diseases.

Traditional South African diets, described since the $1950 \mathrm{~s}$ and known to be associated with low risk of cardiovascular disease $^{6}$, can meet micronutrient requirements under certain circumstances ${ }^{7}$. These are, however, usually not very palatable diets and the movement towards more meat, fish, egg, milk, cheese, bread, margarine, salt, oil, sugar and other sweets, often in the form of fast or convenience foods, is understandable. The knowledge that these diets increase risk of non-communicable disease has stimulated much research on the relationship between specific nutrients and the risk factors of these diseases. But little is known on how to motivate populations in transition to retain the best aspects of their traditional diets, and to avoid the detrimental characteristics of typical Western diets. This challenge has motivated our research group to develop a more holistic approach in examining the nutrition transition in South Africa.

\section{Integration of research concepts}

To gain a better insight into the changes in the lives of populations (and individuals) in transition, how populations respond to these changes, and how this knowledge can be used to promote healthier diets and ways of life, we developed a multidisciplinary research approach. A multidisciplinary team examines how individuals (and populations) in transition cope with or adapt to the changes experienced during urbanisation, acculturation, Westernisation or modernisation.

These changes can be categorised in many ways and include changes in the environment (physical infrastructure, access to health care, income, food, pollution, etc.), changes in society (social support networks, value systems, education, empowerment of women, etc.) and changes on a household and individual level (family structures, values, religious beliefs, attitudes, food security, etc.). These environmental and social as well as biological aspects correspond to the dimensions of the new nutrition science as now proposed ${ }^{2}$.

The disciplines at present involved in the research group are: nutrition, dietetics, physiology, biochemistry, human movement sciences, anthropology, psychology, social work, nursing, theology, agriculture, education and consumer sciences. For implementation of research results in intervention programmes, partnerships with local governance, agriculture and health services are formed.

A basic, underlying hypothesis of the research group is that the way individuals respond to these environmental changes will impact on their health behaviours, food choices, etc. and thus on their risk of disease. Part of this hypothesis is the recognition that the response to changes in the environment will influence, but also be influenced by, psychological strengths, genetics and early (foetal and childhood) programming (biological and psychological).

The disciplines involved in this research are from both the social and natural sciences. At times researchers will work as a multidisciplinary team, approaching the same problem in parallel from different angles. However, mostly the researchers will work transdisciplinarily, integrating research hypotheses, design and methodologies for a more holistic but in-depth understanding of the problem.

This trans- or interdisciplinary approach changed the traditional, narrow research paradigms of the different disciplines. The positivistic, quantitative paradigm of the natural scientists, used to measure and analyse, to reduce problems into controllable size where the researcher is in control, objectively collecting data through repeatable experiments, is now combined with a more imaginative, narrative and qualitative paradigm derived from the social sciences. 


\section{Box 1 - The new nutrition science in studying the nutrition transition in South Africa}

The new nutrition science project proposes that the science has three dimensions: biological, and also environmental and social ${ }^{1}$. Within these dimensions, a number of sub-dimensions or domains are also proposed $^{2}$; these work applied to countries in transition, as shown here. Examples of questions that can be addressed using these domains are also given.

\section{Evolution}

The way humans respond to changes in their environment, including adaptation to new and changing diets, will to a certain extent be determined by evolutionary developments such as genetic profiles, natural selection, and epigenetic changes during foetal exposures.

- What are the strengths in specific populations that protect against development of specific non-communicable diseases (such as high high-density lipoprotein cholesterol of Africans)?

\section{History}

To study and design appropriate interventions to protect against the adverse consequences of the nutrition transition, the history of the particular population is of importance. In South Africa for example, the history and burden of the Apartheid ideology is resulting in an attitude of 'a right to a Western diet' based on previous inequities.

- How could the history of the past Apartheid era be used to promote prudent diets amongst previous disadvantaged populations?

\section{Resources (natural, living, buman)}

The challenge during transition is to use resources responsibly in order to preserve them for the future.

- How should the natural resource of water be utilised in the production of a variety of foods compatible with good health? What indigenous crops, using limited water resources, should be promoted?

\section{Ecology and environment}

In the context of the nutrition transition, the development of dietary recommendations (foodbased dietary guidelines) for optimum nutrition should focus on the production of foods that will be ecological and environmentally friendly. This was one of the reasons why the South African food-based dietary guidelines did not recommend milk as the main dietary source of calcium.
- What foods provide a healthy diet without 'harming' the environment?

- Is it possible to replace staple crops such as maize with indigenous crops such as mabela (sorghum)?

- How can the omega-3 fatty acid intakes of South Africans be increased without relying on traditional Mediterranean and imported sources?

\section{Food systems and agriculture}

Food systems and agriculture are involved on different levels in the nutrition transition. The most important is probably their contribution to food security. South Africa is food-secure on a national level (food is even exported) but not on a household level.

- To what extent will small farm holdings contribute to household food security in the different climatic parts of South Africa?

- What is the best agriculture policy, land ownership, etc., to guarantee food security?

- Are small-scale, household vegetable gardens sufficient to provide needed micronutrients and to protect against non-communicable diseases?

\section{Tradition, culture, cuisine}

The challenge is to develop food policy and dietary recommendations that are culturally sensitive. To do this, much more knowledge on the nutrient contributions, acceptability and palatability of traditional diets and cuisine of the different populations in Africa is necessary. For example, traditionally the Nguni people ate samp and beans together, two plant foods forming a complete protein with all required amino acids. This habit, as well as other foods, is lost during the urbanisation process.

- Why are traditional foods disappearing in the diet during urbanisation? Is it availability, palatability, status symbol reasons, or other?

\section{Technology and industry}

As in the North (Western world), the challenge is to provide safe, nutritional foods at affordable prizes. Fortunately, in addition to high-fat convenience foods and products, some traditional, low-fat, high-fibre products are now becoming available, such as a traditional tinned tomato and onion relish, tinned dry beans and lentils.

- How can industry be motivated to use technologies in the development of more lowenergy-density, safe and nutritious products at affordable prices? 


\section{Physical bealtb (natural, living, buman)}

Choices that consumers make during the nutrition transition (regarding diets/foods and other health behaviours such as smoking, physical activity) will impact on their physical health. It is important to understand why people make certain choices (such as availability, convenience, price, palatability, peer pressure) in order to make recommendations for healthier choices.

- How can populations in transition be influenced to make healthier choices regarding foods eaten and other ways of life?

\section{Mental, emotional and spiritual bealth}

Mental, emotional and spiritual health will influence psychological strengths and the ability of individuals to cope with change. To understand why people make specific lifestyle choices during transition, factors contributing to coping abilities (or the lack thereof) should be examined in more detail.

- What are the factors influencing the development of coping strategies during the transition process?

- What is the role of mental and spiritual health of individuals in creating and maintaining healthy communities?

\section{Equity (including poverty)}

Poverty, being disadvantaged, the status of women, equity, and other factors all influence the way individuals and communities will respond to change during urbanisation and transition.

- What are the differences between male- and femaleheaded households regarding food security?

- How does poverty affect community functioning?

- What are the relationships between poverty and education?
- Are there infrastructures and safety networks to ensure adequate education and training for the poor?

\section{Economics and politics}

The transition in Africa, from rural to urban and from traditional to Westernised ways of life, is accompanied by both improvements and a deterioration in economic circumstances. The development of squatter areas (urban slums) in the developing world is a given. To ensure adequate nutrition in these areas is a huge challenge. Government policies and actions have enormous influence on infrastructures, housing, health systems, food security and social and economic empowerment.

- What are the relationships between income and food expenditure in populations in transition?

- How can individuals and households be motivated and empowered to make healthy choices when other choices become affordable?

\section{Philosopby and etbics}

Philosophical and ethical considerations should influence the design of policy and interventions in communities in transition. This should help to ensure that human rights of individuals in these communities are respected.

- How should ethical considerations be applied in the recommendations, guidelines, information transfer, education and instruction of people in transition to motivate healthier choices in foods and ways of life?

\section{References}

1 The Giessen Declaration. Public Health Nutrition 2005; 8(6A): 783-6.

2 Leitzmann C, Cannon G. Dimensions, domains and principles of the new nutrition science. Public Health Nutrition 2005; 8(6A): 787-94.
This integration of research paradigms has resulted in more holistic research with wider boundaries and a better understanding of the problems. The researchers are now more subjective and participatory, collecting data that are studied and from which theory flows. The researchers are now the learners. As the research group progresses more towards implementation, the paradigm of critical social theory and action research will also become part of the research philosophy.

These developments stimulated a more positive approach with a focus on health, rather than disease. This fortigenic or strength-based paradigm has led to a reformulation of research questions. For example, instead of designing projects to examine the early origins of disease or vulnerability, the question would now be about the early origins of strengths that enable individuals to cope with their changing environments.

\section{Using this bolistic approach}

Our multidisciplinary team has designed, executed and published the data of a series of projects with the main objective to study the interactions between biological, psychosocial and environmental factors that determine the response of individuals and groups in transition to their changing circumstances. Our main hypothesis is that these responses will determine nutritional status and health.

This integrated, transdisciplinary approach is illustrated by our efforts to improve the quality of life of Africans in 
transition infected with HIV. An early observation from the THUSA (Transition and Health during Urbanisation of South Africans) study ${ }^{8}$ was that, amongst 1785 apparently healthy individuals recruited into a baseline epidemiological survey from rural and urban areas in the North-West Province, the prevalence of unknown, asymptomatic HIV infection was higher in the urban poor than in the urban rich or rural poor (Table 1).

The same study ${ }^{9}$ showed that general coping strategies, as measured by the COPE and SACS scales, of infected participants differed significantly from those of uninfected subjects. All psychometric scales used to measure psychological variables were adapted and validated for this population?. HIV uninfected subjects had higher scores for all COPE sub-scales except for alcohol and drug disengagement, for which the higher score was reversed, meaning that the infected subjects had higher involvement with alcohol and drugs.

The infected subjects, therefore, had a lower number of available coping strategies, which was confirmed with the SACS. The uninfected subjects scored higher for both constructive coping strategies such as planning, seeking social support and acceptance, and also for destructive coping strategies such as avoidance, anti-social or instinctive action. These results suggested that general coping strategies as measured in this study may be related to specific, situational, behavioural coping strategies to prevent HIV infection?

Using qualitative methods, Lemke ${ }^{10}$ and Lemke et al. ${ }^{11}$ showed in a sub-sample of this population that $75 \%$ of the households were food-insecure. Food insecurity was related to family disruption due to migrant work, poverty and societal violence. She showed that female-headed households, despite more limited resources, often attained better nutrition security, among other reasons because of fostering of social ties, networking and innovative informal sector activities to increase income.

A comparison of the nutritional status of these asymptomatic infected subjects with uninfected subjects ${ }^{12}$ showed no significant differences in nutrient intakes and anthropometric variables, but significantly lower levels of several biochemical variables indicative of nutritional status and higher levels of liver enzymes. A principal

Table 1 HIV status of South African urban and rural populations

\begin{tabular}{lccccc}
\hline & Group & Group & Group & Group & Group \\
Variable & 1 & 2 & 3 & 4 & 5 \\
\hline Number (men) & 196 & 113 & 134 & 236 & 84 \\
Number (women) & 300 & 148 & 175 & 293 & 106 \\
\% HIV-infected men & 7.4 & 7.8 & 11.1 & 21.9 & 5.8 \\
\% HIV-infected & 8.9 & 8.6 & 17.7 & 12.7 & 9.4 \\
women & & & & & \\
\hline
\end{tabular}

Group (level of urbanisation): 1 - deep rural, traditional villages; 2 - farm dwellers (commercial farms); 3 - informal housing areas (squatter camps); 4 - urban, established townships; 5 - urban, Westernised, professional people.

Adapted from Vorster et al. ${ }^{8}$ components analysis was used to summarise dietary patterns. The first principal component contrasted the intakes between meat, fruit and vegetables in one direction and the consumption of staples (maize meal). A high positive score reflected a diet higher in meat and vegetables and a more negative score, a diet higher in maize products.

Table 2 shows the mean diet score for each third of the distribution of the liver enzyme aspartate aminotransferase (AST) for infected subjects. Those subjects in the lowest third of AST had a statistically significantly higher mean dietary score than subjects in the middle and highest thirds of AST. The diet score further showed statistically significant negative correlations with liver enzymes. These results suggest that a diet higher in meat and vegetables may protect HIV-infected subjects against liver damage $^{12}$. All these results are reflected and used in the design of an integrated intervention study ${ }^{13,14}$ in which a protein and micronutrient supplement was developed based on the staple food of HIV-infected subjects, tested for acceptability ${ }^{15}$ and combined with a social group work programme $^{14}$ to improve quality of life of these subjects, by improving nutritional status and delaying progression of the infection to full-blown AIDS.

The major dimensions of the concept of the new nutrition science are manifest in this integrated intervention study:

- The environmental dimension is reflected in the use of a traditional, locally produced staple food (maize meal) as basis of the supplement ${ }^{13,15}$.

- The social dimension is contained in the design and evaluation of the impact of the social group work programme in which actions that influence knowledge, attitude, behaviour, coping strategies, self-esteem and food security were implemented and strengthened in a culturally sensitive way ${ }^{14}$.

- The biological dimension is displayed in the numerous health outcomes and markers of progression of HIV to AIDS $^{13}$ measured to evaluate the influence of the nutrition supplement and social group work programme.

Table 2 An indication of nutritional status in HIV-infected South Africans

\begin{tabular}{lrrr}
\hline $\begin{array}{l}\text { Thirds of } \\
\text { AST }\end{array}$ & $\begin{array}{c}\text { Mean diet } \\
\text { score }\end{array}$ & $95 \% \mathrm{Cl}$ & $\begin{array}{c}\text { Overall } F \text {-ratio; } \\
P \text {-value }\end{array}$ \\
\hline Lowest & 0.17 & $0.08,0.43$ & $3.04 ; P=0.05$ \\
Middle & -0.19 & $-0.41,0.03$ & \\
Highest & -0.16 & $-0.37,0.06$ & \\
\hline
\end{tabular}

AST - aspartate aminotransferase; $\mathrm{Cl}$ - confidence interval.

Spearman correlations, liver enzymes and diet score: alanine aminotransferase, $-0.19(P=0.007)$; AST, $-0.15(P=0.031)$.

Score derived from first principal component: positive score indicates higher consumption of meat products and vegetables; negative score indicates higher consumption of maize and lower consumption of meat and vegetables.

Adjusted for age, area of residence, gender and year of study (1996, 1998).

Adapted from Vorster et al. ${ }^{12}$. 
Is this integrated approach more successful? The multidisciplinary publications from the research ${ }^{8-22}$ indicate a better understanding of the problems related to the nutrition transition, such as the contribution of psychological factors to the development of hypertension ${ }^{19}$ and obesity $^{23}$. This should, hopefully, lead to better policies, strategies and programmes in the future to address these problems.

An example of the application of research results obtained in these transdisciplinary research studies ${ }^{8-14}$ in multisectoral intervention programmes is the FLAGH (Farm Labour and General Health) project, in which a combination of different interventions is applied to improve the quality of life of farm workers and their families in the North-West Province of South Africa. Preliminary results ${ }^{20-22}$ are promising, indicating that these interventions may be more sustainable because they address multiple needs of populations on different levels.

\section{Conclusion}

One of the major advantages of a holistic, transdisciplinary approach to research on the nutrition transition, with the new conceptual framework proposed by the new nutrition science project, together with integration of qualitative and quantitative research paradigms, is that it opens the door for many different domains within the biological, social and environmental dimensions proposed to be included in the research and practice of nutrition ${ }^{1}$. This holistic approach to nutrition science has also been articulated in the first chapter of a new series of text books ${ }^{24}$.

The biological, societal and environmental dimensions of the new nutrition science, taken all together, are necessary for a better understanding of the nutrition transition.

\section{References}

1 The Giessen Declaration. Public Health Nutrition 2005; 8 (6A): 783-6.

2 Leitzmann C, Cannon G. Dimensions, domains and principles of the new nutrition science. Public Health Nutrition 2005; 8(6A): 787-94.

3 The Health Systems Trust. South African Health Review 2002. Durban: Health Systems Trust, 2002; 546 pp.

4 Vorster HH, Bourne LT, Venter CS, Oosthuizen W. Contribution of nutrition to the health transition in developing countries: a framework for research and intervention. Nutrition Reviews 1999; 57(11): 341-9.

5 MacIntyre UE, Kruger HS, Venter CS, Vorster HH. Dietary intakes of an African population in different stages of transition in the North-West Province, South Africa: the THUSA study. Nutrition Research 2002; 22: 239-56.

6 Walker ARP. Diet and atherosclerosis. Lancet 1955; 2: 565-6.

7 Vorster HH, Venter CS, Mensink E, van Staden DA, Labadarios D, Strydom AJC, et al. Adequate nutritional status despite restricted dietary variety in adult rural Vendas. South African Journal of Clinical Nutrition 1994; 7(2): 3-16.

8 Vorster HH, Wissing MP, Venter CS, et al. The impact of urbanization on physical, physiological and mental health of Africans in the North-West Province of South Africa: the
THUSA study. South African Journal of Sciences 2000; 96 : 505-14.

9 Wissing MP, Vorster HH. General coping strategies related to probability of contracting HIV-infection. Paper presented at the XXVII International Congress of Psychology, Stockholm, Sweden, 23-28 July 2000.

10 Lemke S. Food and nutrition security in black South African households: creative ways of coping and survival. $\mathrm{PhD}$ thesis, University of Munich, Munich, 2001.

11 Lemke S, Vorster HH, Jansen van Rensburg NS, Ziche J. Empowered women, social networks and the contribution of qualitative research: broadening our understanding of underlying causes for food and nutrition insecurity. Public Health Nutrition 2003; 6(8): 759-64.

12 Vorster HH, Kruger A, Margetts BM, Venter CS, Kruger HS, Veldman FJ, et al. The nutritional status of asymptomatic HIV-infected Africans. Directions for dietary intervention? Public Health Nutrition 2004; 7(8): 1055-64.

13 Venter CS, Jerling JC, Oosthuizen W, Hanson P, Mooko M. The effects of an instant soy-maize porridge on the well-being of young HIV-positive volunteers. Presented at Soy \& Health 2002: Clinical Evidence, Dietetic Applications, London, 3031 May 2002.

14 Roux AA, Venter CS, Wessels CC. A group work programme for HIV/AIDS patients. Social Work Practitioner-Researcher 2001; 13(2): 33-47.

15 Scholtz SC, Bosman MJC. HIV positive and negative consumers accept an instant soy maize porridge [abstract]. South African Journal of Clinical Nutrition 2002; 15(Suppl. 2): S9.

16 Kruger HS, Venter CS, Vorster HH. Obesity in African women in the North-West Province, South Africa is associated with an increased risk of non-communicable diseases: the THUSA study. British Journal of Nutrition 2002; 86: 733-40.

17 Kruger MC, De Winter RM, Becker PJ, Vorster HH. Changes in markers of bone turnover following urbanisation in black South Africa women. Journal of Endocrinology, Metabolism and Diabetes of South Africa (JEMDSA) 2004; 9(1): 8-14.

18 Manyedi ME, Koen MP, Greeff M. Experiences of widowhood and beliefs about the mourning process of the Batswana people. Health South Africa Gesondheid 2004; 8(4): 69-87.

19 Van Rooyen JM, Nienaber AW, Huisman HW, Schutte AE, Malan NT, Schutte $\mathrm{R}$, et al. Differences in resting cardiovascular parameters in 10- to 15-year-old children of different ethnicity: the contribution of physiological and psychological factors. Annals of Behavioral Medicine 2004; 28(3): 163-70.

20 Prinsloo A, Pienaar AE. Prevalence of developmental co-ordination disorder and influences of physical activity levels and body composition on the children of farm dwellers: FLAGH-study. African Journal for Physical, Health Education, Recreation and Dance (AJPHERD) 2003; 9(1): $151-64$.

21 Phometsi M, Kruger A, Van't Riet H. Nutrition knowledge and barriers to dietary practices among school children in a farming community - FLAGH-programme. Development South Africa 2005; in press.

22 Strydom H. Perception and needs of farm dwellers on ageing, advanced age and future perspectives. Journal of Gerontological Social Work 2003; 42(1): 59-76.

23 Schutte AE, Kruger HS, Wissing MP, Underhay C, Vorster HH. The emergence of the metabolic syndrome in urban obese African women: the POWIRS study. South African Journal of Science 2005; 101: 61-7.

24 Vorster HH, Hautvast J. Introduction to human nutrition: a global perspective on food and nutrition. In: Gibney MJ, Vorster HH, eds. Introduction to Human Nutrition. Oxford: Blackwell, 2002; 1-11. 